\title{
Comparative epidemiology of stroke and acute myocardial infarction: the Dijon Vascular Project (DIVA)
}

\author{
Arnaud Gentil, MD; Yannick Béjot, MD; Luc Lorgis, MD; Jérôme Durier, PhD ; \\ Marianne Zeller, PhD; Guy-Vicor Osseby, MD; Gilles Dentan, MD; Jean-Claude Beer, \\ MD; Thibault Moreau, MD; Maurice Giroud, MD; Yves Cottin, MD.
}

From the Dijon Stroke Registry (AG, YB, JD, GVO, TM, MG) (EA 4184). University of Burgundy, University Hospital and Faculty of Medicine of Dijon, Dijon, France ; the Observatoire des Infarctus de Côte-d'Or (RICO) (LL, MZ, JCB, YC), LPPCE, IFR SantéSTIC, University of Burgundy, University of Hospital and Faculty of Medicine of Dijon, Dijon, France ; and the Cardiology Department (GD), Clinique de Fontaine, 21121 Fontaine les Dijon, France.

A. Gentil and Y. Béjot have contributed equally to this work.

\section{Correspondence to:}

Dr Yannick BEJOT

Department of Neurology

University Hospital - 3 Rue du Faubourg Raines

21000 DIJON

Phone: (33) 3.80.29.32.45

Fax: (33) 3.80.29.32.45

Email: ybejot@yahoo.fr 


\section{Key-words:}

Population-based study; Stroke; Acute myocardial infarction; Incidence; Case-fatality

\section{Word count:}

3590 words

Abstract: 239 words

\section{ACKNOWLEDGEMENTS:}

This work was supported by a grant from the University Hospital of Dijon and the Regional Council of Burgundy in 2006. The sponsors of the study had no role in the project, in data collection, data interpretation and analysis, or in writing the publication. The corresponding had full access to all of the data in the study and takes responsibility for the integrity of the data and the accuracy of the data analysis.

We thank Mr Philip Bastable for reviewing the English.

\section{CONFLICTS OF INTEREST:}

None 


\section{Abstract}

\section{Background:}

Despite a common pathophysiological mechanism, i.e. atherosclerosis, and similar vascular risk factors, few reliable studies have compared the epidemiology of stroke and acute myocardial infarction (AMI).

\section{Methods:}

We prospectively recorded all first-ever cases of stroke and AMI in Dijon, France $(151,846$ inhabitants) from 2001 to 2006. The 30-day case fatality rates (CFR) and the vascular risk factors were assessed in both groups.

\section{Results:}

Over the 6 years, we recorded 1660 events (1020 strokes and 640 AMI). Crude incidence of stroke was higher than that of AMI (112 versus 70.2/100 000/year, $\mathrm{p}<0.001)$. With regard to the sex, the relative incidence of stroke compared to AMI was 0.88 (95\% CI 0.60-1.29, $\mathrm{p}=0.51)$ in women $<65$ years, and $2.32(95 \%$ CI 1.95-2.75, $\mathrm{p}<0.001)$ in those $>65$ years, whereas it was $0.60(95 \%$ CI $0.42-0.86, \mathrm{p}<0.001)$ in men below 55 years, $1.01(0.81-1.24$, $\mathrm{p}=0.96)$ in those between 55 and 75 years and $2.01(95 \%$ CI 1.48-2.71, p<0.001) at 75 years and older. CFR at 30 days were similar for stroke and AMI (9.80 \% versus $9.84 \%, \mathrm{p}=0.5)$. Hyperglycemia (>7.8 mmol/l) at onset was significantly associated with higher CFR in both stroke and AMI patients. The prevalence of male sex, hypercholesterolemia, and diabetes was higher in AMI patients whereas hypertension was more frequent in stroke patients.

\section{Conclusion:}

Our findings will help health care authorities to evaluate future needs for stroke and AMI services, and to develop secondary prevention strategies. 


\section{Introduction}

Stroke and acute myocardial infarction (AMI) are the most prevalent chronic diseases, in both developed [1] and developing countries.[2-3] These two diseases share not only a common pathophysiological mechanism, ie atherosclerosis, but also vascular risk factors such as high blood pressure, tobacco smoking, high body mass index, hypercholesterolemia and diabetes. They also share preventive treatments and a similar need for acute emergency care. In addition, they are a leading cause of premature death and physical disability.[1,3-4] Nevertheless, AMI and stroke have rarely been analysed together by large, prospective population-based studies to determine the relative incidence and outcome within the same population. Indeed, the Monica Project included certain types of events and limited ascertainment to people between 34 and 65 years.[5] Only the Oxford Vascular Study (Oxvasc) reported specific data from an unselected population of 91106 people in Oxfordshire and demonstrated that the incidence of stroke was higher than that of AMI.[6] France is characterized by strikingly low incidence and case fatality rates for coronary and cerebral vascular diseases despite the burden of vascular risk factors. This so-called French paradox is probably due to the specific nature of the French diet and alcohol consumption.[78] Hence, it appears essential to obtain reliable information about the comparative epidemiology and the relative clinical burdens of stroke and AMI in France to enable health care organizations to prepare for future health care needs..

Therefore, from a large population-based study conducted in the whole population of the City of Dijon, we aimed to prospectively ascertain the overall incidence and 30-day case-fatality of first-ever acute stroke and AMI over a 6-year period (2001-2006). 


\section{Methods}

Our study was based on both the Dijon Stroke Registry, which has been running since 1985,[9-10] and the Registry of myocardial infarction of Dijon and Côte d'Or (Rico) [11] which was launched in 2001. Data from these two registries between 2001 and 2006 have been pooled in a retrospective analysis for a collaborative study called the DIjon VAscular (Diva) project.

\section{Study area and population:}

The studied population was that of the city of Dijon comprising 151,846 inhabitants (82 144 women and 69702 men). Fifteen percent of the population were 65 years old or older. Less than $5 \%$ of migration was observed over the study period with no change in the economic status.

\section{Ascertainment of stroke}

\section{Case ascertainment}

Since 1985, the stroke Registry of Dijon has been using a constant prospective method of ascertainment, for patients of all ages, and without interruption. A detailed description of the Dijon Stroke Registry has been published elsewhere.[9-10] To ensure the completeness of case ascertainment, information was provided by five sources: (1) the emergency rooms, and all of the clinical and radiological departments of Dijon University Hospital; (2) the emergency rooms and all of the clinical departments of the 3 private hospitals of the city and its suburbs; (3) the patient's home or from the nursing homes of the city, with diagnosis 
assessed by the 250 general practitioners (GPs) with the help of an outpatients clinic; (4) the 3 private radiological centres, where the medical records were reviewed to identify missed cases that had not been transferred to the Registry by the general practitioners; (5) the ultrasound Doppler centres of the University Hospital and private centres, where medical records were reviewed. Stroke was defined according to World Health Organization (WHO) recommendations and according to the International Classification of Disease.

\section{Diagnosis of stroke subtypes and classification}

The diagnosis of stroke subtypes was always performed on clinical criteria, cerebral imaging (CT-scan and/or MRI examination), and complementary investigations including EKG, echocardiography, cervical artery ultrasonography, and standard blood and urine tests.[9-10] We included (1) ischemic strokes from lipohyalinosis of small arteries, so-called lacunar infarct (LI); (2) ischemic strokes from cardiac embolism (CE) originating from atrial fibrillation $(\mathrm{AF})$, or valve disease, patent foramen ovale or spontaneous intracavitar thrombus; (3) other ischemic strokes defined by focal cortical symptoms, and cortical infarct on a large vascular territory on CT or MRI. This group included ischemic strokes from atheroma of large arteries, and ischemic stroke from other or undetermined causes (unfortunately, these different types of ischemic strokes were not separated in our registry (IS)); (4) primary cerebral hemorrhagic $(\mathrm{PCH})$ and (5) subarachnoid hemorrhagic (SAH) stroke. When it was difficult to differentiate between IS, LI and CE strokes, medical staff meetings were held to classify the difficult cases into 1 of the 3 categories.

\section{Ascertainment of acute myocardial infarction}


The design and methods of the population-based Rico survey have been published.[11] Briefly, since January 1, 2001, the Rico registry has been collecting data from patients hospitalized with AMI in the City of Dijon and in 5 cities of the Côte d'Or area. To ensure the completeness of case ascertainment, the collaboration of GPs and private cardiologists was also required in order to identify patients who had suffered an AMI without hospitalisation in one of the cities. For the Diva study, only AMI patients residing in Dijon were considered. Both ST-elevation MI (STEMI) and Non-ST-elevation MI (NSTEMI) were diagnosed according to the European Society of Cardiology and the American College of Cardiology criteria.[11] Data were collected at each site by a study coordinator trained in completing the core record form and in extracting data from medical records, using a standardized case report form. Cases were ascertained by prospective collection.

\section{Vascular risk factors and follow-up for stroke and AMI}

Vascular risk factors were collected by the 2 teams for stroke and AMI with a common methodology as previously described.[9-11] Hypertension was defined by history of known hypertension (systolic blood pressure $\geq 140 \mathrm{mmHg}$ and/or diastolic blood pressure $\geq 90$ $\mathrm{mmHg}$ ) or antihypertensive treatment. Diabetes mellitus was recorded if a glucose level of $\geq 7.8 \mathrm{mmol} / \mathrm{l}$ had been reported in the medical record or if the patient was under insulin or oral hypoglycemic agents. Hypercholesterolemia was defined by total cholesterol level $\geq 5.7$ $\mathrm{mmol} / \mathrm{l}$. We also recorded tobacco use (1 cigarette per day, current or former habit), and atrial fibrillation (AF) diagnosed from EKG or Holter recordings. For stroke, a history of TIA and previous AMI were recorded, and for AMI, a history of TIA and stroke were collected.

After hospital discharge, information at 30 days was acquired by contacting patients individually or their relatives or treating physician, and by reviewing the hospital records if 
the patient had been rehospitalized. For patients who had died from stroke or AMI in the prehospital setting, the death certificates were obtained from the database of the Regional Health Service in charge of recording deaths in the region of Côte d'Or. Information on case fatalities gathered from these various sources for the whole study population was thus complete.

\section{Statistical analysis}

To measure the incidence rates, the National Institute of Statistics provided census data for 1982, 1990 and 1999 for the population in Dijon in l-year age groups and by sex. The population was estimated from these censuses by extrapolation. Age-specific and sex-specific incidence rates per 100,000 of the population per year were calculated for all cases of firstever stroke and AMI, for incident events and for 30-day case-fatality rates. Although all comparisons were made within the same population, rates were standardized to any French, European and World population to allow comparisons with data from the literature. We calculated $95 \%$ CIs using the Poisson distribution. Differences with regard to age, sex and disease rates were investigated by Poisson regression analyses. The Incidence Rate Ratio (IRR) by sex, age $(<55,55-75,>75)$ and event was calculated. Case-fatality rates (CFR) were based on survival after 30 days and trends were evaluated with linear regression. Univariate and multivariate analyses were performed using logistic regression to identify the determinants of death before 30 days for stroke and myocardial infarction. The variables included were the time period (2001-2002, 2003-2004, 2005-2006), age, sex, hypertension, hypercholesterolemia, diabetes, initial glycemia, tobacco consumption, history of Transient Ischemic Attack (TIA), atrial fibrillation, and either history of AMI and stroke subtype for stroke patients or history of stroke for AMI patients. Odds Ratios and their 95 CIs were 
calculated for all the variables in the univariate analysis, and only independent variables were included in the multivariate model. Overall survival was calculated by the Kaplan-Meier method. The survival curves calculated by univariate analysis were compared using the LogRank test.

The statistical analysis was performed with STATA 9.0 software and a level of $\alpha=0.05$ was used to evaluate the results.

\section{Ethics}

The Diva project was approved by the Ethics Committee of the University Hospital of Dijon.

\section{Results}

\section{Distribution of incidence rates of stroke and AMI}

Over the whole study period, 1660 events were recorded. Among these, 1020 (485 men and 535 women) were first-ever stroke $(61.4 \%)$ and 640 (403 men and 237 women) were AMI (38.6\%). The distribution of stroke subtypes was $104 \mathrm{PCH}(10 \%) 19 \mathrm{SAH}(2 \%)$ and 897 ischemic strokes $(88 \%)$. Among these, we observed 267 lacunar strokes $(29.8 \%), 181$ cardioembolic strokes $(20.2 \%)$, and $449(50 \%)$ ischemic strokes from atheroma of large arteries, other and undetermined causes. Identification was based on the first clinical report in 853 cases $(83.5 \%)$, by first cerebral imaging in 122 cases (12\%) and by first ultrasonography in 30 cases $(3 \%)$. Only 15 cases $(1.5 \%)$ were ascertained from the death certificate. Cerebral imaging was performed in 999 cases (98\%). For AMI, identification was based on the first clinical report in all but 2 cases, which were based on death certificates. 
Annual age-specific and sex-specific incidence rates for stroke and AMI rose steeply with age. In men, the mean age at onset was 7 years higher for stroke than for AMI $(71.5 \pm 13.1 \mathrm{vs}$ $64.9 \pm 12.7$ years, $\mathrm{p}=0.01)$. In women, the age at event onset was similar $(75.3 \pm 13.3$ vs $75.2 \pm 13.5$ years, $\mathrm{p}=0.5)$. The annual incidence of stroke was $98.5 / 100,000$ for ischemic strokes, 11.4/100,000 for $\mathrm{PCH}$ and 2.1/100 000 for SAH. Incidence rates adjusted to French, European and world populations were significantly higher for stroke than for AMI (Table 1). The relative incidence of stroke compared to myocardial infarction was 0.88 (95\% CI 0.60 $1.29, \mathrm{p}=0.51)$ in women $<65$ years, and $2.32(95 \%$ CI 1.95-2.75, $\mathrm{p}<0.001)$ in those $>65$ years (Figure 1). The incidence of stroke became significantly higher than that of AMI from the age group 65-69 years onwards (95\% CI: 1.05-3.39; $\mathrm{p}=0.035)$. The relative incidence was $0.60(95 \%$ CI 0.42-0.86, $\mathrm{p}<0.001)$ in men below 55 years, 1.01 (95\% CI 0.81-1.24, p=0.957) in those between 55 and 75 years and $2.01(95 \%$ CI 1.48-2.71, p<0.001) at 75 years and older (Figure 2).

\section{Distribution of case-fatality rates at $\mathbf{3 0}$ days for stroke and AMI}

Case fatality rates (CFR) at 30 days were $9.80 \%$ for stroke versus $9.84 \%$ for AMI without any significant difference (log rank test=0.946) (Figure 3). Nevertheless, differences between stroke subtypes were observed, with lower 30-day CRF in lacunar stroke (1.5\%, 95\% CI 0.573.94) than ischemic strokes from atheroma of large arteries, other and undetermined causes (10\%, 95\% CI 13.2-17.6), cardioembolic stroke (13.3\%, 95\% CI 9.1-19.1), and hemorrhagic stroke $(22 \%, 95 \%$ CI $15.6-30.4)$.

Using multivariate regression analyses, the independent determinants for CFR at day 30 for stroke patients were age $\geq 85$ years, cardio-embolic and hemorrhagic strokes, the first study period (2001-2002), history of AMI and glycemia at onset $>7.8 \mathrm{mmol} / \mathrm{l}$. For AMI patients, 
age $\geq 85$ at onset, the first study period 2001-2002, history of hypercholesterolemia, diabetes, tobacco consumption as well as glycemia at onset $>7.8 \mathrm{mmol} / \mathrm{l}$, were associated with increased mortality at 30 days.

\section{Vascular risk factors for stroke and AMI}

The distribution of the various vascular risk factors for stroke and myocardial infarction is listed in Table 2. The proportion of men (63\% versus $47.5 \%, \mathrm{p}<0.001)$, hypercholesterolemia (41.5\% versus $33.8 \%, \mathrm{p}=0.002)$ and diabetes $(21.6 \%$ versus $17.5 \%$, $\mathrm{p}=0.004$ ) was greater in MI than in stroke, while the proportion of blood hypertension was higher in stroke $(65.8 \%$ versus $51.0 \%, \mathrm{p}<0.001)$. A history of AMI was observed in $15 \%$ (12.8-17.2) of the stroke patients, while a history of stroke was present in $7.6 \%$ (5.6-9.7) of the patients with an AMI. A history of TIA and AF was present in respectively $8.8 \%$ (7.1-10) and $22.4 \%(19.9-25)$ of the stroke patients.

The prevalence of risk factors in both stroke and AMI patients by sex and age groups is shown in table 3. Whatever the sex and the age, glycemia at onset was higher in AMI patients than in stroke patients. In men, the prevalence of hypertension and tobacco use was higher in stroke patients than in AMI patients from the age 55-75 onwards. In women with AMI, the

prevalence of hypercholesterolemia was higher in the age group $<65$ years, as was the prevalence of diabetes in the age group $>65$ years.

\section{Discussion}

Diva is a reliable population-based registry that has collected data on acute stroke and AMI over a period of 6 years. Data were obtained from numerous sources, there was no age limit, 
post-mortem and death certificates were checked prospectively and the cardiology and neurology departments coordinated their efforts. Using data from this registry, we demonstrated here that first-ever stroke was more frequent than first-ever AMI in women aged $>65$ years and in men $>75$ years. In contrast, in men $<55$ years, AMI was more frequent than stroke. In addition, for the first time, the distribution of risk factors was compared between stroke and AMI patients in a large comprehensive population-based study. Such data are of interest in order to design and implement effective secondary prevention strategies.

\section{Diva and vascular epidemiology}

In the literature about vascular epidemiology, many incomplete studies have reported a decreasing incidence of AMI, stroke events and mortality. These studies, however, had some major biases: a) the majority were either hospital-based, or had age limitations, including individuals younger than 65 years,[12] from 30 to 60 years,[13] between 45 and 64 years [14] or older than 35 years;[15] b) several cardiovascular epidemiology studies included only selected volunteers rather than unselected population cohorts;[14] c) some studies were restricted to patients aged 35-74 years admitted to hospitals with AMI,[14] or to coronary and peripheral vascular events in patients with diabetes.[16] Furthermore, Diva covered the largest population (151,864 inhabitants), versus 5209 in Framingham,[13] and 17792 in ARIC.[14] In our study, the distribution of vascular risk factors of both stroke and AMI were similar to those of the literature [17-21] as was the distribution of stroke subtypes. Only Oxvasc was able to report all coronary, cerebral, and peripheral vascular events.[6]

\section{Diva and Oxvasc}

In Dijon, both the incidence rates and the distribution of stroke mechanisms and subtypes, and AMI were comparable to those described in Oxvasc despite the large size of the Diva 
population (150 000) compared to the Oxvasc population (91106). [6] However, differences between Dijon and Oxford have been brought to light.

Firstly, in Dijon, the mean age at AMI onset was significantly lower than that for stroke in men, whereas there was no difference in Oxford. This correlates with the higher incidence of AMI than of stroke in men $<55$ years in our study.

Secondly, in contrast with Oxvasc, our study did not include TIA and unstable angina. We could argue that TIA and unstable angina should not be included in a comparison of clinical burden. Therefore, we preferred to study first-ever stroke and AMI to compare the natural history of these 2 diseases. In Oxvasc, among the 1657 study patients, the relative rates for acute cerebrovascular events versus coronary events were 1.07 (95\% CI 0.98-1.18, p=0.14) overall, and $0.97(0.87-1.08, \mathrm{p}=0.57)$ if TIA and unstable angina were excluded. Nevertheless, considering only first-ever events, the incidence of stroke was higher only in women $>75$ years, whereas, in our study, it was higher both in women $>65$ years and in men $>75$ years. Moreover, in Dijon, the incidence of AMI was higher than that of stroke in men below 55 years, which was not the case in Oxvasc. Hence, to understand the different incidence patterns of stroke and AMI in our population, we analysed the distribution of premorbid risk factors by sex and age groups. Indeed, it has been suggested that the strength of the association of a given atherothrombotic risk factor varies for different vascular beds (stroke, AMI, peripheral arterial disease). Hence, hypertension appeared to be a risk factor strongly associated with stroke, whereas hypercholesterolemia was more strongly related to AMI. [22] Nevertheless, in our study, the prevalence of hypertension and tobacco use was higher in male stroke patients compared with male AMI patients, not only in the age group $>75$ years, but also in that 55-75 years, whereas in the latter, no difference in the incidence of the two vascular events was noted. In women with AMI, the prevalence of hypercholesterolemia was higher in the age group $<65$ years, as was the prevalence of diabetes in the age group $>65$ years. Therefore, 
these results suggest that the distribution of classical atherothrombotic risk factor does not totally explain the incidence patterns of stroke and AMI.

The similarity between CFR for stroke and AMI observed in Diva was not observed in Oxvasc where the CFR for AMI was lower than that for stroke. This could suggest that in Dijon, the organization of health systems and acute medical strategies for stroke and AMI are very similar, using the same care systems. The low CFR of $9 \%$ observed in stroke in Diva was similar to that in Oxvasc.[6] Finally, we observed the negative impact of hyperglycemia at onset on prognosis as previously described for stroke and AMI.[23-24]

Our findings for AMI in young men have important implications in that they emphasize the need to develop and generalize primary prevention for AMI in young men. Our findings in older age groups suggest that it is necessary to implement an efficient public health policy for primary prevention of stroke in older people. Moreover, there is a need for randomised trials to analyse the effectiveness of prevention or treatment strategies for cerebral and cardiac events in elderly people.

The major advantage of our study is the continuous ascertainment from 2001 to 2006, in a well defined population, and the collaboration of numerous investigators from all fields of patient management, which ensured the exhaustiveness of case ascertainment. In addition, the population of the city was very stable with less than $5 \%$ of migration, which avoids bias due to changes in ethnic mix, and there was no change in the economic status of local residents. Diagnosis of the stroke subtype was precise thanks to neuroimaging, since CT scan was performed in more than $98 \%$ of cases.

However, our study has several possible limitations. Although methods for case ascertainment and criteria were consistent throughout the study period, the incidence of stroke could have been over-estimated in the last study periods compared to the first one because of the 
improvement in diagnostic techniques with the use of MRI. Nevertheless, access to this technique was limited since only $26 \%$ of stroke patients had MRI examination over the 6 years, and there were no major changes between 2001 and 2006. Furthermore, improvements in the diagnosis of less severe strokes may have been counterbalanced by the fact that the true incidence of non-disabling stroke may have been underestimated because patients with mild symptoms may have not taken medical advice and so may have not been registered. In addition, we were only able to classify ischemic strokes according to 3 subtypes instead of using the Toast Classification.[25] Actually, the Toast classification has been used in the Dijon Stroke Registry since January 2005. Before this period, ischemic strokes were classified as lacunar infarcts, cardioembolic strokes, or other ischemic strokes including stroke from atheroma of large arteries. Hence, to avoid retrospective diagnostic bias, we chose to limit our study to this classification. Another limitation is that our largely white population with a high socioeconomic level did not allow us to compare the distribution of vascular events according to ethnic groups.

The case ascertainment of AMI may have been non exhaustive since the registry of AMI was more recently launched, suggesting an underestimation of the crude incidence of AMI in the first years, despite a multiple sources in hospital and community of Dijon. Although AMI is usually associated with severe symptoms, unrecognized or silent AMI might have been missed by our case ascertainment procedure. As the incidence of unrecognized AMI increases with age, it might have resulted in an underestimation of the crude incidence. Nevertheless, the recent estimates of the rates of unrecognized AMI show that they are in true decline. Awareness of the symptoms and signs of AMI has probably improved over time as a result of a community education campaign. Moreover, for the ascertainment of AMI, the use of biomarkers such as troponin certainly improved the diagnosis of AMI in elderly people, and 
case-fatality is very similar to case-fatality reported in current registries of acute AMI, suggesting that this potential bias had little impact on our results.

In conclusion, our population-based study demonstrates a higher incidence of stroke in men aged $>75$ years and in women aged $>65$ years, contrasting with a higher incidence of AMI in men $<55$ years. The mean age at onset was 7 years lower for AMI than for stroke in men only, whereas no difference was found for CFR at 30 days. Our findings underline the need to put stroke and AMI on an equal footing with regard to health policy.

\section{Acknowledgements:}

This work was supported by a grant from the University Hospital of Dijon and the Regional Council of Burgundy in 2006. The sponsors of the study had no role in the project, in data collection, data interpretation and analysis, or in writing the publication. The corresponding had full access to all of the data in the study and takes responsibility for the integrity of the data and the accuracy of the data analysis.

We thank Mr Philip Bastable for reviewing the English.

\section{Competing interests:}

The authors report no conflicts of interest.

"The Corresponding Author has the right to grant on behalf of all authors and does grant on behalf of all authors, an exclusive licence (or non exclusive for government employees) on a worldwide basis to the BMJ Publishing Group Ltd and its Licensees to permit this article (if 
accepted) to be published in Thorax editions and any other BMJPGL products to exploit all subsidiary rights, as set out in our licence" 


\section{References}

1. Fuster V. Epidemic of cardiovascular disease and stroke: the three main challenges. Circulation. 1999;99:1132-1137.

2. Yusuf S, Reddy S, Ounpuu S, et al. Global burden of cardiovascular disease. Part II: variations in cardiovascular disease by specific ethnic groups and geographic regions and prevention strategies. Circulation. 2001;104:2855-2864.

3. Ezzati M, Hoorn SV, Rodgers A, et al. Comparative Risk Assessment Collaborating Group. Estimates of global and regional potential health gains from reducing multiple major risk factors. Lancet. 2003;362:271-280.

4. Donnan GA, Fisher M, Macleod M, et al. Stroke. Lancet. 2008;371:1612-1623.

5. Truelsen T, Mähönen M, Tolonen $\mathrm{H}$, et al. Trends in stroke and coronary heart disease in the WHO MONICA PROJECT. Stroke. 2003;34:1346-1352.

6. Rothwell PM, Coull AJ, Silver LE, et al. Population-based study of event-rate, incidence, case-fatality and mortality for all acute vascular events in all arterial territories (Oxford Vascular Study). Lancet. 2005;366:1773-1783.

7. Law M, Wald N. Why heart disease mortality is low in France: the time lag explanation. BMJ. 1999;318:1471-1476.

8. Criqui MH, Ringel BL. Does diet or alcohol explain the French Paradox? Lancet. 1994;344:1719-1723.

9. Benatru I, Rouaud O, Durier J, et al. Stable stroke incidence rates but improved case-fatality in Dijon, France, from 1985 to 2004. Stroke. 2006;37:1674-1679.

10. Bejot Y, Rouaud O, Durier J, et al. Decrease in the stroke case-fatality-rates in a French population-based twenty-years study. A comparison between men and women. Cerebrovasc Dis. 2007;24:439-444. 
11. Zeller M, Steg PG, Ravisy J, et al. Prevalence and Impact of Metabolic Syndrome on Hospital Outcomes in Acute Myocardial Infarction. Arch Int Med. 2005;165:11921198.

12. Asplund K. What MONICA told us about stroke. Lancet Neurol. 2005; 4:64-68.

13. Fox CS, Evans JC, Larson MG, et al. Temporal trends in coronary heart disease mortality and sudden cardiac death from 1950 to 1999. The Framingham Heart Study. Circulation. 2004;110:522-527.

14. The ARIC investigators. The Atherosclerosis Risk in Communities (ARIC) study: design and objective. Am J Epidemiol. 1989;129:687-702.

15. Rosamond W, Flegal K, Furie K, et al. for the American Heart Association Statistics Committee and Stroke Statistics Subcommittee. Heart disease and stroke statistics 2008 update : a report from the American Heart Association Statistics Committee and stroke statistics subcommittee. Circulation. 2008;117:25-146.

16. Elveback LR, Connolly DC, Melton LJ 3rd. Coronary heart disease in residents of Rochester, Minnesota. VII. Incidence, 1950 through 1982. Mayo Clin Proc. 1986;61:896-900.

17. EUROCISS Working Group. Coronary and cerebro-vascular population-based registers in Europe: are morbidity indicators comparable? Results from the EUROCISS Project. Eur J Public Health. 2003;13(3 suppl):55-60.

18. For the WHO MONICA Project. MONICA, Monograph and Multimedia Sourcebook. The World's Largest Study of Heart Disease, Stroke, Risk factors, and population Trends (1979-2002). Genova, World Health Organization 2003. 
19. Palmieri L, Barchielli A, Cesana G, et al. The Italian register of cardiovascular diseases: attack rates and case fatality for cerebrovascular events. Cerebrovasc Dis. 2007;24:530-539.

20. Muntner P, DeSalvo KB, Wildman RP, et al. Trends in the prevalence, awareness, treatment and control of cardiovascular disease risk factors among noninstitutionalized patients with a history of myocardial infarction and stroke. Am J Epidemiology. 2006;163:913-920.

21. Iso $\mathrm{H}$, Sato $\mathrm{S}$, Kitamura $\mathrm{A}$, et al. Metabolic syndrome and the risk of ischemic heart disease and stroke among Japanese men and women. Stroke. 2007;38:1744-1751.

22. Lewington S, MacMahon S. Blood pressure, cholesterol, and common causes of death: a review. Prospective Studies Collaboration. Am J Hypertens. 1999;12:96S98S.

23. Baird TA, Parsons MW, Phanh T, et al. Persistent poststroke hyperglycemia is independently associated with infarct expansion and worse clinical outcome. Stroke. 2003;34:2208-2214.

24. Zarich SW, Nesto RW. Implications and treatment of acute hyperglycemia in the setting of acute myocardial infarction. Circulation. 2007;115:e436-e439.

25. Adams HP Jr, Bendixen BH, Kappelle LJ, et al. Classification of subtype of acute ischemic stroke. Definitions for use in a multicenter clinical trial. TOAST. Trial of Org. 10172 in Acute Stroke Treatment. Stroke. 1993;24:35-41. 
Table 1: Crude and adjusted to World and European population incidence of stroke and AMI by sex.

\begin{tabular}{|c|c|c|c|c|c|c|c|c|c|c|c|c|c|c|c|c|c|c|c|c|c|c|c|c|c|}
\hline \multirow{3}{*}{ age } & & \multicolumn{8}{|c|}{ Men } & \multicolumn{9}{|c|}{ Women } & \multicolumn{7}{|c|}{ Men and Women } \\
\hline & \multirow{3}{*}{$\begin{array}{c}\text { At risk/year } \\
31556\end{array}$} & \multicolumn{4}{|c|}{ Acute myocardial infarction } & \multicolumn{4}{|c|}{ Stroke } & \multirow[b]{2}{*}{ At risk/year } & \multicolumn{4}{|c|}{ Acute myocardial infarction } & \multicolumn{4}{|c|}{ Stroke } & \multicolumn{3}{|c|}{ Acute myocardial infarction } & \multicolumn{4}{|c|}{ Stroke } \\
\hline & & \multirow{2}{*}{$\begin{array}{l}\mathrm{N} \\
1\end{array}$} & \multirow{2}{*}{$\begin{array}{l}\text { Rate } \\
0.5\end{array}$} & \multicolumn{2}{|c|}{$(95 \% \mathrm{Cl})$} & \multirow{2}{*}{$\begin{array}{l}\mathrm{N} \\
3\end{array}$} & \multirow{2}{*}{$\begin{array}{c}\text { Rate } \\
1.6\end{array}$} & \multicolumn{2}{|c|}{$(95 \% \mathrm{Cl})$} & & \multirow{2}{*}{$\begin{array}{l}\mathrm{N} \\
\mathrm{O}\end{array}$} & \multirow{2}{*}{$\begin{array}{c}\text { Rate } \\
0.0\end{array}$} & \multicolumn{2}{|c|}{$(95 \% \mathrm{Cl})$} & & \multirow{2}{*}{$\begin{array}{l}\text { Rate } \\
5.1 \quad\end{array}$} & \multicolumn{2}{|c|}{$(95 \% \mathrm{Cl})$} & Rate & (95 & $\% \mathrm{Cl}$ & Rate & & $(95 \%)$ & $\% \mathrm{Cl}$ \\
\hline$<30$ & & & & 0.0 & -2.91 & & & $(\quad 0.3$ & - 4.6 ) & 35797 & & & 0.0 & - 1.4 ) & $\begin{array}{l}N \\
11\end{array}$ & & 2.6 & - 9.2 ) & 0.21 & 0.0 & - 1.4 ) & 3.5 & 1 & 1.9 & - 5.8 \\
\hline $30-35$ & 5594 & 4 & 11.9 ( & 3.2 & $-30.5)$ & 6 & 17.9 & $(\quad 6.6$ & - 38.9 ) & 5199 & 1 & 3.21 & 0.1 & $-17.9)$ & 8 & $25.6 i$ & 11.1 & - 50.5 ) & $7.7 i$ & 2.5 & $18.0)$ & 21.6 & 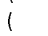 & 11.8 & - 36.3 \\
\hline $35-40$ & 4535 & 6 & 22.1( & 8.1 & $-48.0)$ & 3 & 11.0 & ( $\quad 2.3$ & - 32.2 ) & 4590 & 2 & $7.3 i$ & 0.9 & $-26.2)$ & 9 & $32.7 i$ & 14.9 & - 62.0 ) & $14.6 i$ & 6.3 & - 28.8 ) & 21.9 & ( & 11.3 & - 38.3 \\
\hline $40-45$ & 4068 & 24 & $98.3 i$ & 63.0 & $-146.3)$ & 8 & $32.8 i$ & ( 14.2 & - $64.6 j$ & 4744 & 6 & $21.1 i$ & 7.7 & $-45.9 j$ & 7 & $24.6 i$ & 9.9 & - 50.7 ) & $56.7 i$ & 38.3 & $81.0 j$ & 28.4 & i & 15.9 & - 46.8 \\
\hline $45-50$ & 5037 & 30 & $99.3 i$ & 67.0 & $-141.7)$ & 22 & 72.81 & $(45.6$ & - 110.2$)$ & 5725 & 6 & $17.5 i$ & 6.4 & $-38.0)$ & 16 & $46.6 i$ & 26.6 & $75.6 j$ & $55.8 i$ & 39.1 & 77.21 & 58.9 & ( & 41.6 & - 80.8 \\
\hline $50-55$ & 4971 & 44 & $147.5 i$ & 107.2 & - 198.1$)$ & 24 & 80.5 & ( 51.6 & - 119.7 ) & 5522 & 9 & $27.2 i$ & 12.4 & $-51.6)$ & 19 & $57.3 i$ & 34.5 & - 89.6 ) & $84.2 i$ & 63.1 & $-110.1)$ & 68.3 & i & 49.4 & - 92.0 \\
\hline $55-60$ & 2882 & 51 & 294.9 । & 219.6 & -387.8 ) & 33 & 190.8 & ( 131.4 & -268.0 ) & 2893 & 13 & $74.9 i$ & 39.9 & - 128.1$)$ & 11 & $63.4 i$ & 31.6 & - 113.4 ) & 184.7 i & 142.3 & -235.9 ) & 127.0 & & 92.3 & - 170.5 \\
\hline $60-65$ & 23 & 42 & 304.4 & 219.4 & -411.5 ) & 39 & 282.7 & i 201.0 & - 386.4 ) & 2662 & 13 & $81.4 !$ & 43.3 & - 139.2) & 21 & 131.5 ( & 81.4 & - 201.0 ) & 184.8 i & 139.2 & $-240.5)$ & 201.6 & i & 153.8 & - 259.4 \\
\hline $65-70$ & 2 & 35 & 261.3 ( & 182.0 & $-363.4)$ & 44 & 328.5 & ( 238.7 & -441.0 ) & 2865 & 17 & $98.9 i$ & 57.6 & - 158.4$)$ & 32 & $186.2 !$ & 127.4 & $262.8)$ & $170.0 i$ & 127.0 & 223.01 & 248.5 & $(1$ & 195.8 & - 311.1 \\
\hline $70-75$ & 2318 & 44 & $316.4 i$ & 229.9 & $-424.7)$ & 57 & $409.8 i$ & ( 310.4 & -531.0 ) & 3771 & 21 & $92.8 i$ & 57.5 & $-141.9)$ & 48 & $212.2 i$ & 156.4 & $-281.3)$ & $177.9 i$ & 137.3 & $-226.8)$ & 287.4 & , & 235.1 & - 347.9 \\
\hline $75-80$ & & 51 & $392.9 i$ & 292.5 & $-516.6)$ & 99 & $762.7 i$ & ( 619.8 & - $928.5 j$ & 3824 & 43 & 187.4 & 135.6 & $-252.4)$ & 87 & $379.2 i$ & 303.7 & - $467.7 j$ & $261.7 i$ & 211.4 & $-320.2)$ & 517.7 & & 446.0 & - 597.7 \\
\hline$>80$ & 2046 & 71 & $578.4 i$ & 451.7 & $-729.5)$ & 147 & 1197.5 & （ 1011.7 & $-1407.4)$ & 4556 & 106 & $387.8 i$ & 317.5 & $-469.0)$ & 266 & $973.2 i$ & 859.7 & $-1097.4)$ & $446.9 i$ & 383.5 & $517.8)$ & 1042.7 & & 944.5 & -1148.3 \\
\hline $\begin{array}{l}\text { adjusted to world } \\
\text { population }\end{array}$ & & & 69.41 & 62.1 & -76.81 & & 69.6 & 62.6 & - 76.5 I & & & 21.1 & 17.6 & -24.61 & & 44.7 & 39.7 & $49.6 \quad$ & 43.01 & 39.1 & 46.81 & 55.2 & & 51.0 & - 59.3 \\
\hline $\begin{array}{l}\text { adjusted to european } \\
\text { population }\end{array}$ & 69704 & 403 & 99.01 & 89.4 & - 118.6$)$ & 485 & 105.9 & ( 95.6 & - 116.3 ) & 82148 & 237 & 32.11 & 26.4 & - 37.91 & 535 & 66.51 & 58.3 & $\begin{array}{lll}- & 74.7 \quad \text { ) }\end{array}$ & 62.11 & 54.4 & 69.81 & 82.9 & & 73.7 & - 92.1 \\
\hline $\begin{array}{l}\text { adjusted to french } \\
\text { population }\end{array}$ & & & 118.8( & 107.1 & $-130.5)$ & & 147.2 & ( 134.1 & - 160.4 ) & & & 43.81 & 38.1 & -49.61 & & 95.3 & 86.9 & - 103.6 ) & 76.21 & 70.2 & $95.7 \quad)$ & 115.8 & ( & 108.6 & - 123.0 \\
\hline
\end{tabular}


Table 2: prevalence of vascular risk factors in AMI and stroke

\begin{tabular}{lccc}
\hline & AMI & Stroke & p value \\
\hline Number & 640 & 1020 & \\
Male & $63.0 \%(59.2-66.7)$ & $47.5 \%(44.5-50.6)$ & $<0.001$ \\
Hypertension & $51.0 \%(47.1-54.9)$ & $65.8 \%(62.9-68.7)$ & $<0.001$ \\
Hypercholesterolemia & $41.5 \%(37.6-45.4)$ & $33.8 \%(30.9-36.7)$ & 0.002 \\
Diabetes & $21.6 \%(18,4-24,8)$ & $17.5 \%(15.2-19.9)$ & 0.004 \\
Glycemia at onset & $9.1(8.6-9.6)$ & $6.9(6.8-7.1)$ & $<0.001$ \\
(mmol/l) & & & \\
Tobacco use & $29.0 \%(25.4-32.5)$ & $28.3 \%(25.3-31.4)$ & 0.786 \\
\hline
\end{tabular}


Table 3: prevalence of vascular risk factors by sex and age groups

\begin{tabular}{|c|c|c|c|}
\hline \multicolumn{4}{|c|}{ Men } \\
\hline & AMI & Stroke & $\mathrm{p}$ \\
\hline \multicolumn{4}{|l|}{ Age $<55$} \\
\hline$N$ & 109 & 66 & \\
\hline Hypertension & $27.5 \%(19.0-36.0)$ & $39.4 \%(27.3-51.5)$ & 0.103 \\
\hline Hypercholesterolemia & $40.0 \%(30.5-49.5)$ & $37.9 \%(25.9-49.9)$ & 0.782 \\
\hline Diabetes & $8.3 \%(3.0-13.5)$ & $13.6 \%(5.1-22.1)$ & 0.256 \\
\hline Glycemia at onset $(\mathrm{mmol} / \mathrm{l})$ & $7.56(6.74-8.39)$ & $6.56(5.70-7.41)$ & $<0.001$ \\
\hline Tobacco use & $66.7 \%(57.6-75.7)$ & $57.9 \%(44.7-71.1)$ & 0.265 \\
\hline \multicolumn{4}{|l|}{ Age 55-75 } \\
\hline$N$ & 223 & 271 & \\
\hline Hypertension & $47.3 \%(40.7-53.9)$ & $70.1 \%(64.6-75.6)$ & $<0.001$ \\
\hline Hypercholesterolemia & $42.7 \%(36.0-49.3)$ & $38.0 \%(32.2-43.8)$ & 0.297 \\
\hline Diabetes & $26.0 \%(20.2-31.8)$ & $21.0 \%(16.2-25.9)$ & 0.193 \\
\hline Glycemia at onset $(\mathrm{mmol} / \mathrm{l})$ & $8.93(8.33-9.53)$ & $7.20(6.84-7.57)$ & $<0.001$ \\
\hline Tobacco use & $30.9 \%(24.8-37.1)$ & $50.6 \%(44.3-57.0)$ & $<0.001$ \\
\hline \multicolumn{4}{|l|}{ Age $>75$} \\
\hline$N$ & 71 & 148 & \\
\hline Hypertension & $50.7 \%(38.6-62.8)$ & $74.7 \%(67.5-81.8)$ & $<0.001$ \\
\hline Hypercholesterolemia & $36.9 \%(24.9-49.0)$ & $26.7 \%(19.5-34.0)$ & 0.135 \\
\hline Diabetes & $19.7 \%(10.2-29.2)$ & $14.3 \%(8.6-20.0)$ & 0.306 \\
\hline Glycemia at onset $(\mathrm{mmol} / \mathrm{l})$ & $7.86(7.19-8.52)$ & $6.88(6.32-7.43)$ & $<0.001$ \\
\hline Tobacco use & $11.8 \%(3.9-19.6)$ & $36.6 \%(28.0-45.2)$ & $<0.001$ \\
\hline \multicolumn{4}{|c|}{ Women } \\
\hline & AMI & Stroke & $\mathrm{p}$ \\
\hline \multicolumn{4}{|l|}{ Age $<65$} \\
\hline$N$ & 67 & 134 & \\
\hline Hypertension & $50.7 \%(38.6-63.0)$ & $45.1 \%(36.5-53.7)$ & 0.451 \\
\hline Hypercholesterolemia & $54.5 \%(42.2-66.9)$ & $30.1 \%(22.2-38.0)$ & 0.001 \\
\hline Diabetes & $19.4 \%(9.7-29.1)$ & $16.5 \%(10.1-22.9)$ & 0.615 \\
\hline Glycemia at onset $(\mathrm{mmol} / \mathrm{l})$ & $8.91(6.87-10.94)$ & $6.76 \quad(6.31-7.22)$ & 0.006 \\
\hline Tobacco use & $40.3 \%(28.2-52.4)$ & $26.8 \%(18.5-35.1)$ & 0.060 \\
\hline \multicolumn{4}{|l|}{ Age $>65$} \\
\hline$N$ & 170 & 401 & \\
\hline Hypertension & $71.4 \%(64.5-78.3)$ & $70.8 \%(66.3-75.3)$ & 0.877 \\
\hline Hypercholesterolemia & $37.4 \%(29.9-44.9)$ & $34.2 \%(29.5-38.9)$ & 0.465 \\
\hline Diabetes & $25.3 \%(18.6-32.0)$ & $17.2 \%(13.5-21.0)$ & 0.028 \\
\hline Glycemia at onset $(\mathrm{mmol} / \mathrm{l})$ & $11.04(9.56-12.52)$ & $6.88(6.64-7.13)$ & $<0.001$ \\
\hline Tobacco use & $4.2 \%(1.1-7.4)$ & $3.8 \%(1.7-5.8)$ & 0.791 \\
\hline
\end{tabular}




\section{Figure legends:}

Figure 1: Age-specific incidence rates of stroke and AMI in women.

Figure 2: Age-specific incidence rates of stroke and AMI in men.

Figure 3: Kaplan-Meier estimates of 30-day survival of AMI and stroke. 


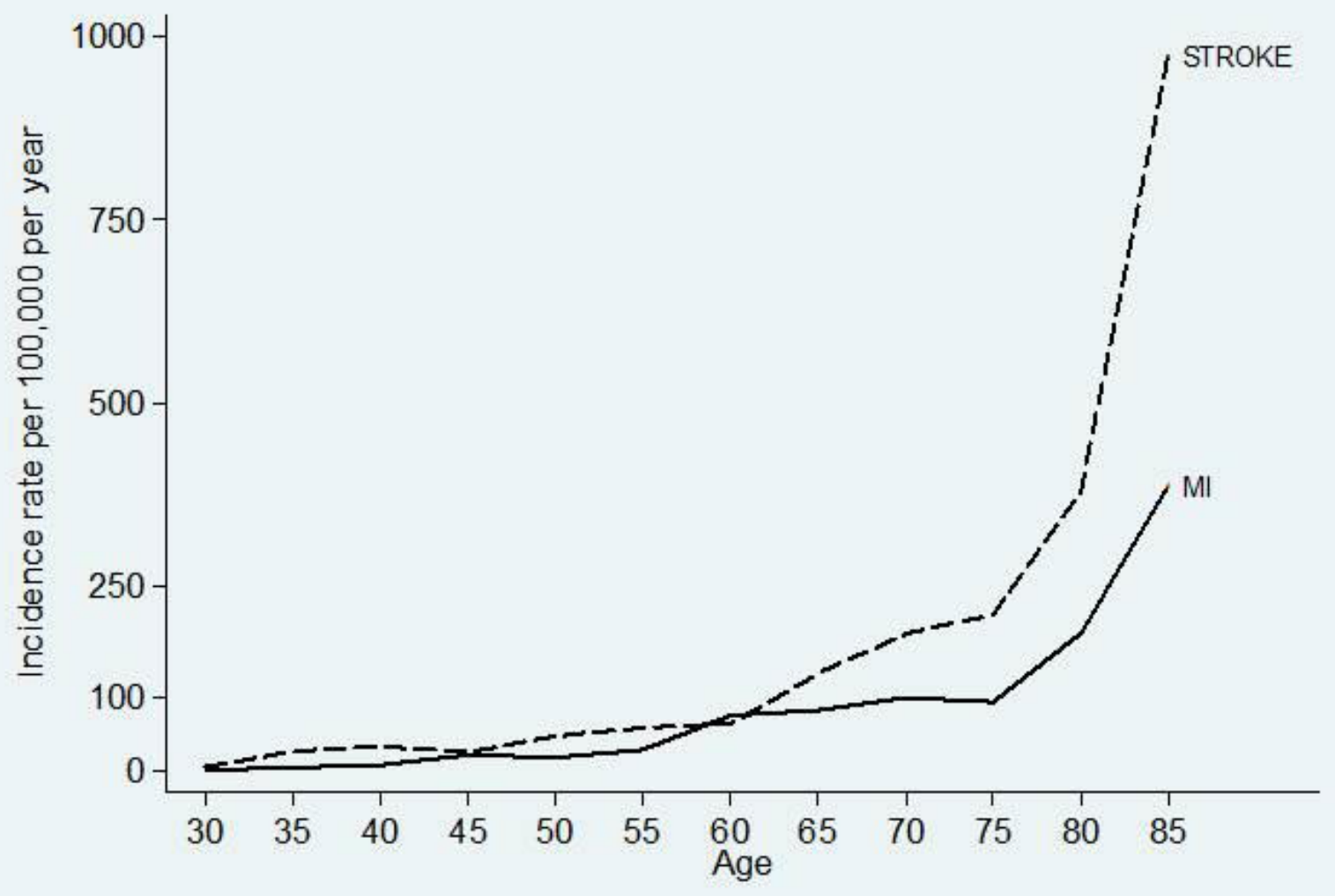




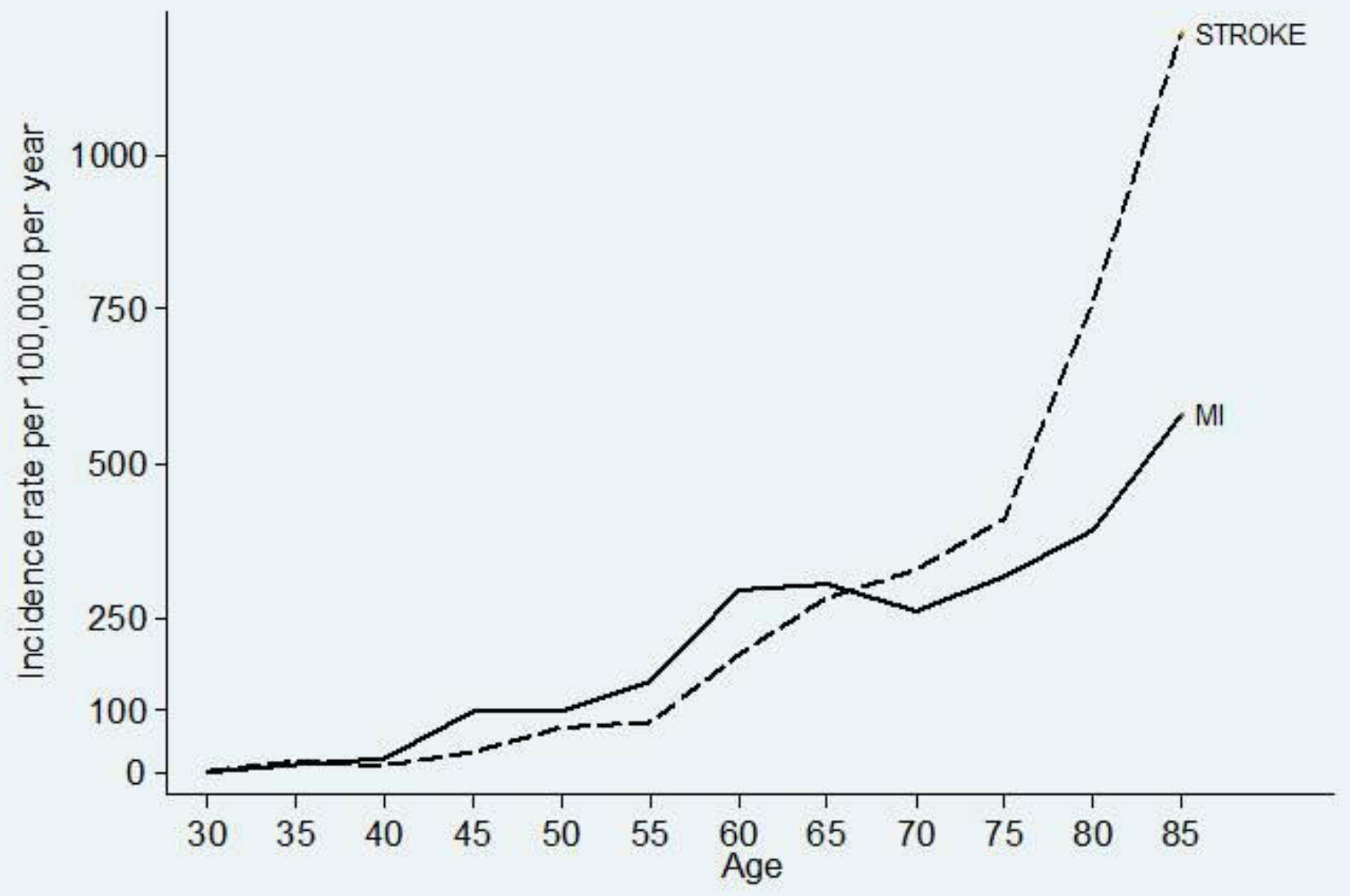




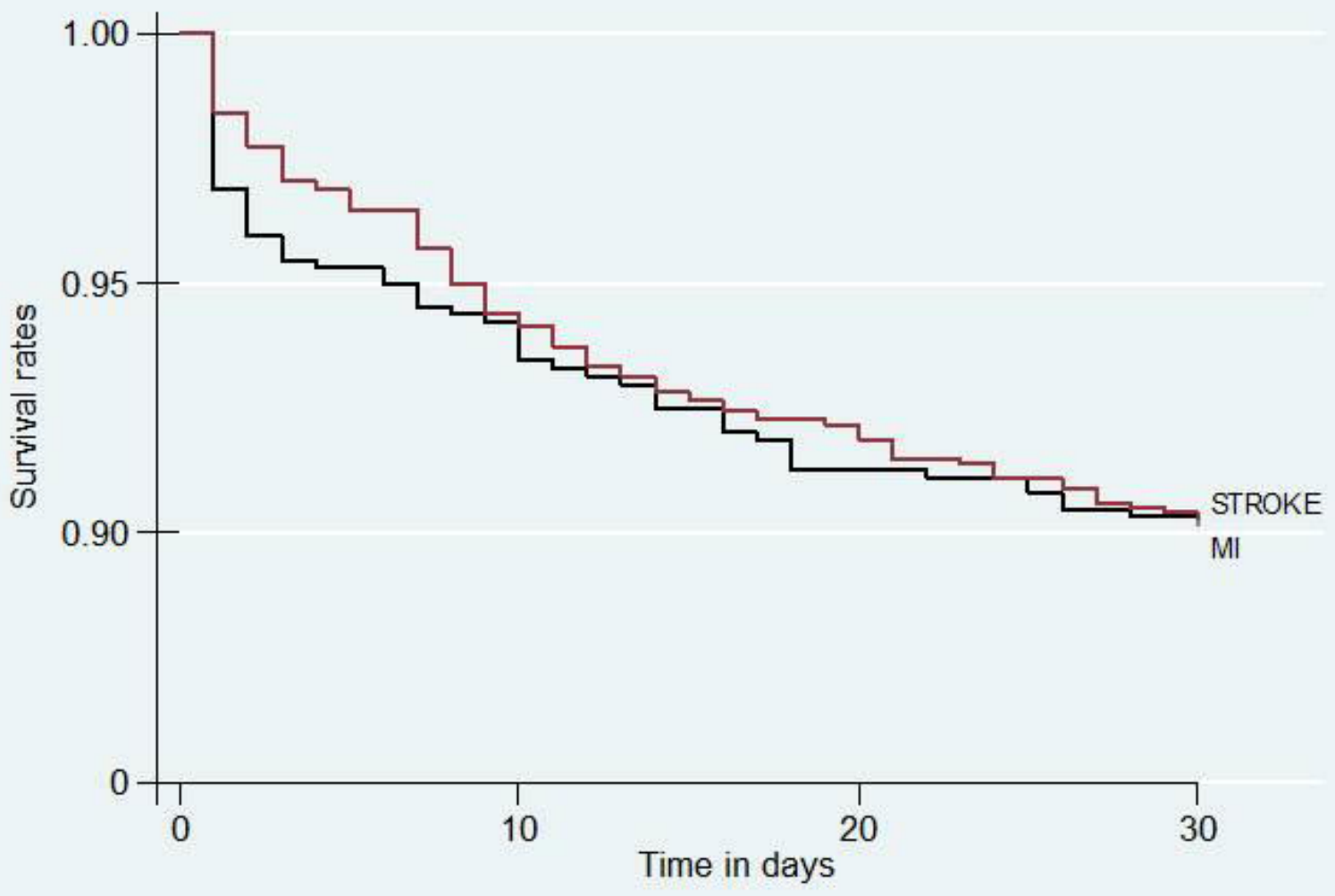

